Check for updates

Cite this: New J. Chem., 2017, 41,7151

Received 11th April 2017 Accepted 9th June 2017 DOI: 10.1039/c7nj01209h rsc.li/njc

\title{
The first electrochemical and surface analysis of 2-aminobenzimidazole as a corrosion inhibitor for copper in chloride solution
}

\author{
Klodian Xhanari (iD ${ }^{\text {ab }}$ and Matjaž Finšgar (D) *a \\ For the first time, 2-aminobenzimidazole (2-ABI) was tested as a corrosion inhibitor for copper in $3 \mathrm{wt} \%$ \\ $\mathrm{NaCl}$ solution at $25^{\circ} \mathrm{C}$ using cyclic voltammetry (CV), chronopotentiometry, electrochemical impedance \\ spectroscopy (EIS), and potentiodynamic curve (PD) techniques. The EIS measurements indicated that \\ the corrosion of $\mathrm{Cu}$ in the presence of 2-ABI followed kinetic- and diffusion-controlled processes. After \\ $100 \mathrm{~h}$ of immersion, the potentiodynamic curves showed that 2-ABI acts as a mixed-type inhibitor, with \\ a predominant action on the anodic corrosion reaction. ATR-FTIR confirmed the adsorption of 2-ABI on \\ the $\mathrm{Cu}$ surface, which resulted in increased hydrophobicity of the copper surface and reduced its \\ surface roughness.
}

\section{Introduction}

Copper is extensively used in a wide range of applications, including structures open to the atmosphere, heat exchangers in marine environments, freshwater supply lines, industrial, chemical, and power-generating plant equipment and electronic devices. ${ }^{1,2}$ The selection of copper is due to the combination of its excellent electrical and thermal conductivity, wide range of attainable mechanical properties, and its ease of fabrication, joining, and soldering. In addition, copper shows resistance to biofouling. ${ }^{1,3}$ Although the corrosion rates of copper in non-oxidizing acids, water, and unpolluted air are negligible, its corrosion susceptibility increases in oxidizing acids, oxidizing heavy-metal salts, sulfur, ammonia, and chloride-containing solutions., ${ }^{2,4}$ Different approaches have been considered to minimize the corrosion of copper, ${ }^{5-7}$ among which the use of organic corrosion inhibitors is by far the one most frequently explored. ${ }^{4,8}$ Azoles have been extensively tested as corrosion inhibitors for copper in different solutions $^{9-13}$ due to the presence of $\mathrm{N}$-atoms in a fivemembered ring as potential adsorption centers. The azole compounds inhibit the corrosion of copper by adsorbing on the metal surface through the free electron pairs in these atoms. Benzotriazole and imidazole derivatives are the two main groups of azole compounds that have been tested in particular as corrosion inhibitors for copper in chloride-containing solutions.

\footnotetext{
${ }^{a}$ University of Maribor, Faculty of Chemistry and Chemical Engineering, Smetanova ulica 17, 2000 Maribor, Slovenia. E-mail: matjaz.finsgar@um.si; Tel: +38622294447

${ }^{b}$ University of Tirana, Faculty of Natural Sciences, Boulevard "Zogu I", 1001 Tirana, Albania
}

Benzotriazole (BTAH) is well known for its corrosion inhibition efficiency for copper in various solutions, ${ }^{4}$ including also chloride-containing solutions. ${ }^{14-20}$ The adsorption of BTAH on the copper surface and the formation of the $\mathrm{Cu}(\mathrm{I}) \mathrm{BTA}$ complex was reported to be the main inhibition mechanism for this compound. ${ }^{4}$ Several BTAH derivatives have also been investigated as corrosion inhibitors for copper in chloride-containing solutions. ${ }^{18,21,22}$

The same inhibition mechanism as for BTAH (adsorption followed by the formation of the surface complex) was proposed for imidazole. ${ }^{8}$ The influence of different substitution groups on the inhibition efficiency of imidazole derivatives was also investigated. ${ }^{23-25}$ Otmačić and Stupnišek-Lisac ${ }^{25}$ investigated the inhibition efficiency of imidazole and its derivatives, i.e. 4-methylimidazole, 4-methyl-1(4-methoxyphenyl)imidazole, 1-( $p$-tolyl)-4-methylimidazole, and 1-phenyl-4-methylimidazole in sodium chloride solutions. They concluded that the inhibition efficiency increased with increasing molecular weight and with the presence of the phenyl ring. The inhibition of the last two imidazole derivatives increased with increasing $\mathrm{pH}$, due to the stronger adsorption of the neutral imidazole molecule, as expected at high $\mathrm{pH}$ values. ${ }^{24}$ The higher efficiency of the mercapto-substituted imidazoles is connected to the stronger bond they form with the surface due to their tendency to deprotonate upon adsorption. ${ }^{23}$

Herein, 2-aminobenzimidazole (2-ABI) was tested in chloride-containing solution and the results were compared to previous studies of 1-hydroxybenzotriazole (BTAOH) and $\mathrm{BTAH},{ }^{14}$ 2-mercaptobenzimidazole (MBIH) ${ }^{26,27}$ 2-mercaptobenzoxazole $(\mathrm{MBOH}){ }^{28}$ 2-mercaptobenzothiazole (MBTH), ${ }^{29}$ and 4-methyl-2-phenyl-imidazole (MePhI), ${ }^{30}$ performed under 


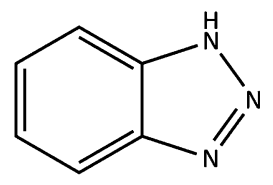

benzotriazole (BTAH)

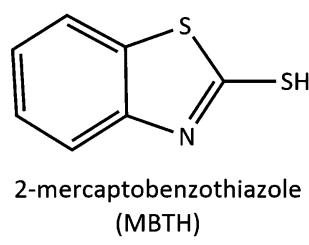

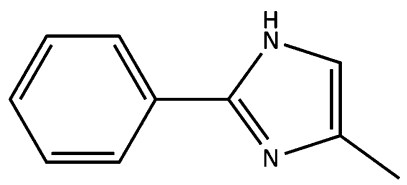

4-methyl-2-phenylimidazole (MePhl)

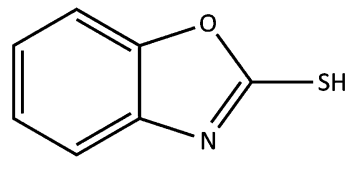

2-mercaptobenzoxazole (MBOH)<smiles>Nc1nc2ccccc2[nH]1</smiles>

2-aminobenzimidazole (2-ABI)<smiles>On1nnc2ccccc21</smiles>

1-hydroxybenzotriazole (BTAOH)<smiles>Sc1nc2ccccc2[nH]1</smiles>

2-mercaptobenzimidazole (MBIH)

Fig. 1 The structures of 2-ABI and the other azole compounds previously tested as corrosion inhibitors for copper under similar conditions. ${ }^{14,26-30}$

similar conditions. 2-ABI is a benzimidazole (BI) derivative consisting of a combination of a benzene and an imidazole ring in which one hydrogen atom is substituted by an amine group. Fig. 1 shows the structures of 2-ABI and the abovementioned azole compounds.

The first reports concerning the use of 2-ABI as a corrosion inhibitor are for 70-30 brass in $1.0 \mathrm{M}$ ammonia solution. ${ }^{31,32}$ The authors reported that 2-ABI acted as a mixed-type inhibitor and attributed its inhibition action to the formation of a protective film of $\mathrm{Cu}(\mathrm{II})$ and $\mathrm{Zn}$ (II) complexes on the brass surface. $^{31}$

2-ABI has been tested mainly as a corrosion inhibitor for steel in acidic ${ }^{33-36}$ and chloride-containing solutions. ${ }^{37-39}$ Popova et al. ${ }^{36}$ compared 2-ABI with $\mathrm{BI}$ and $\mathrm{MBIH}$ as corrosion inhibitors for mild steel in $1 \mathrm{M} \mathrm{HCl}$ solution. They reported that 2-ABI demonstrated the highest inhibition efficiency and chemisorbed on the steel surface. A bond is formed between the free electrons of nitrogen in the imidazole ring in 2-ABI and the vacant d-orbitals in iron. ${ }^{33,36}$ However, Zhang et al. ${ }^{33}$ reported a combination of physisorption and chemisorption as the possible adsorption mechanism for 2-ABI on mild steel in $1 \mathrm{M} \mathrm{HCl}$ solution. The same adsorption mechanism was previously reported by Ghanbari et al. ${ }^{35}$ for 2-ABI on mild steel in $1 \mathrm{M} \mathrm{H}_{3} \mathrm{PO}_{4}$ solution. Based on potentiodynamic polarization measurements, they concluded that 2-ABI acted as a mixed-type inhibitor in both acid solutions. ${ }^{33,35}$ Finšgar et al. ${ }^{39}$ reported that 2-ABI showed corrosion inhibition for mild steel in $3 \mathrm{wt} \%$ $\mathrm{NaCl}$ solution at $25{ }^{\circ} \mathrm{C}$, but not at $70{ }^{\circ} \mathrm{C}$. At both temperatures, the corrosion inhibition efficiency increased with the addition of KI. The corrosion inhibition of 2-ABI for steel in 2.5 and
$3.5 \mathrm{wt} \% \mathrm{NaCl}$ solutions was found to be higher compared with 5 -( $p$-tolyl)-1,3,4-triazole. ${ }^{38}$ The authors attributed this to the planar orientation of 2-ABI facilitating the coverage of the metal surface.

A $3 \mathrm{wt} \% \mathrm{NaCl}$ solution is a highly corrosive environment, and the resulting higher corrosion rates more starkly evidence the inhibition action of the inhibitor to be tested. Hitherto, to the best of our knowledge, this is the first study reporting the inhibition efficiency of 2-ABI in the corrosion of copper in chloride-containing solutions. The selected corrosion inhibitor concentration ( $1 \mathrm{mM}$ ) is close to the $0.1 \mathrm{wt} \%$ inhibitor concentration that is frequently employed for corrosion tests in industry. ${ }^{40}$ In addition, the $1 \mathrm{mM}$ inhibitor concentration chosen will enable direct comparison of 2-ABI with other azole compounds tested previously as corrosion inhibitors for copper in $3 \mathrm{wt} \% \mathrm{NaCl}$ solution. ${ }^{14,26-30}$

The aim of this work is to investigate the inhibition efficiency of 2-ABI in the corrosion of copper in $3 \mathrm{wt} \% \mathrm{NaCl}$ solution at room temperature. First, CV measurements were performed after a short period of immersion $(1 \mathrm{~h})$ to understand the influence of 2-ABI on the oxidation and reduction behavior of copper immersed in $3 \mathrm{wt} \% \mathrm{NaCl}$ solution. Next, EIS was employed to investigate the corrosion mechanism of copper in the presence of 2-ABI after a long period of immersion (up to $100 \mathrm{~h}$ ). The inhibitor type was defined using PD measurements. Finally, surface analyses (i.e. ATR-FTIR contact angle, 3D-profilometry and FE-SEM measurements) were performed in order to prove the adsorption of 2-ABI and its influence on the surface roughness and hydrophobicity of the copper samples. 


\section{Experimental}

\subsection{Sample and solutions preparation}

Copper (99.999\% purity) in the form of $2 \mathrm{~mm}$ thick foil, temper Half Hard, was supplied by Goodfellow (Cambridge, UK). The copper samples used for the immersion tests were cut into rectangular shapes with dimensions of $50 \mathrm{~mm} \times 20 \mathrm{~mm} \times$ $2 \mathrm{~mm}$ and used for immersion tests. Disc-shaped samples with a diameter of $15 \mathrm{~mm}$ were cut out and used for the electrochemical measurements. The sample preparation procedure, including grinding and cleaning in an ultrasonic bath (with a $50 \mathrm{vol} \%$ ethanol $/ 50 \mathrm{vol} \%$ ultrapure water mixture) is the same as reported previously. ${ }^{14,27-30}$

2-ABI with purity $>99$ wt\% was supplied by Acros Organic (New Jersey, USA), while $\mathrm{NaCl}$ and ethanol (for analysis-ACS quality) were supplied by Carlo Erba Reagents (Milan, Italy). All of the $3 \mathrm{wt} \% \mathrm{NaCl}$ solutions with and without the addition of $1 \mathrm{mM}$ 2-ABI were prepared using ultrapure water (with a resistivity of $18.2 \mathrm{M} \Omega \mathrm{cm}$ ) obtained from Milli-Q, Millipore Corporation (Massachusetts, USA). All the experiments were carried out at $25{ }^{\circ} \mathrm{C}$.

\subsection{Immersion tests}

The samples prepared as described above were weighed before being immersed in closed vials (volume of $100 \mathrm{~mL}$ ) in a nonstirring $3 \mathrm{wt} \% \mathrm{NaCl}$ solution with or without the addition of $1 \mathrm{mM} 2$-ABI for 31 days at $25{ }^{\circ} \mathrm{C}$. In order to avoid crevice corrosion, the samples were in contact with the vial only at the four edges. At the end of the immersion period, the samples were first treated as described before ${ }^{27-30,39}$ and then weighed again. The average mass loss was calculated based on three replicate measurements. Possible outliers were checked according to ref. 41 but none was detected.

\subsection{Electrochemical measurements}

The electrochemical measurements were performed in a closed-to-air, three-electrode cell, under stagnant conditions at $25{ }^{\circ} \mathrm{C}$, using the same equipment and reference and counter electrodes as described before. ${ }^{27,28,30}$ The working electrode consisted of a disc-shaped sample embedded in a Teflon holder, with a $1 \mathrm{~cm}^{2}$ area exposed to the solution. All potentials reported herein refer to the saturated calomel electrode, SCE $(0.244 \mathrm{~V} v s$. SHE). CV measurements were performed after $1 \mathrm{~h}$ of immersion in the potential range from $-0.800 \mathrm{~V}$ to $1.000 \mathrm{~V} v s$. SCE using a potential scan rate of $20 \mathrm{mV} \mathrm{s}^{-1}$. Chronopotentiometry measurements were performed starting from the moment of immersion and in between the EIS measurements. The EIS spectra were recorded at different immersion times $(1,3,5,10,30,50$, and $100 \mathrm{~h})$ in the frequency range from $1 \mathrm{MHz}$ to $5 \mathrm{mHz}$ using 10 points per decade and a $10 \mathrm{mV}$ (peak to peak) amplitude of the excitation signal at the open circuit potential, $E_{\text {oc }}$. The EIS response obtained was fitted based on equivalent electrical circuits (EECs), using the Gamry EChem Analyst software. At least three replicate measurements were performed and the average values are presented after discarding outliers using Grubb's chemometric test. ${ }^{41}$ The potentiodynamic curve (PD) measurements started at $-0.250 \mathrm{~V} v s . E_{\mathrm{oc}}$ after $100 \mathrm{~h}$ of immersion. A potential scan rate of $0.1 \mathrm{mV} \mathrm{s}^{-1}$ was employed to increase the potential in the anodic direction. Three replicate measurements were performed in each case and the most representative curve was reported.

\subsection{Surface characterization}

Contact angle and attenuated total reflectance Fourier transform infrared spectroscopy (ATR-FTIR) measurements were performed on the disc-shaped samples after immersion for $1 \mathrm{~h}$ in $3 \mathrm{wt} \% \mathrm{NaCl}$ solution with and without the addition of $1 \mathrm{mM}$ of 2-ABI. After immersion, the samples were rinsed with ultrapure water and dried under a stream of nitrogen. The contact angles were measured using a Krüss DSA 20 tensiometer (Krüss GmbH, Hamburg, Germany). Drop shape analysis software was used to determine the contact angle of a deionized water drop on the surface of the samples. The average value of at least three replicate measurements for samples immersed in $3 \mathrm{wt} \% \mathrm{NaCl}$ solution, with and without the addition of $1 \mathrm{mM}$ 2-ABI, was reported (possible outliers were checked according to ref. 41 but none was detected). A Shimadzu IRAffinity-1 (Colombia, MD, USA) spectrometer was used to perform the ATR-FTIR analysis.

Additional surface characterization of the copper samples immersed for 31 days in $3 \mathrm{wt} \% \mathrm{NaCl}$ solution, with and without the addition of $1 \mathrm{mM} 2$-ABI was performed through $3 \mathrm{D}$-profilometry measurements and field emission scanning electron microscopy (FE-SEM) analysis. The surface topography of the copper samples was investigated using a profilometer, model Form Talysurf Series 2 (Taylor Hobson), with a vertical resolution of about $5 \mathrm{~nm}$. A spot size of $4 \mathrm{~mm}^{2}$ was analyzed. The data were processed using TalyMap Gold 4.1 software and the average surface roughness was calculated. In addition, the surface profile was created. The general geometrical shape and possible measurement-induced misfits were corrected to level the profile. ${ }^{27,28}$ Several measurements in parallel directions $10 \mu \mathrm{m}$ apart were combined to obtain the topography of the surface. A Supra 35 VP (Carl Zeiss, Germany) FE-SEM was employed to analyze the surface morphology of the copper samples.

\section{Results and discussion}

\subsection{Immersion tests}

The copper samples immersed in $3 \mathrm{wt} \% \mathrm{NaCl}$ solution containing $1 \mathrm{mM}$ 2-ABI showed mass gain after 31 days. This is most likely a result of deposition of corrosion products on the sample surface, which were not possible to remove with the procedure used. However, the fact that no mass loss was measured after such a long immersion time is an indication of the high corrosion inhibition efficiency of 2-ABI. The latter was further investigated using electrochemical techniques.

\subsection{CV measurements}

The cyclic voltammograms of the copper samples after $1 \mathrm{~h}$ of immersion in $3 \mathrm{wt} \% \mathrm{NaCl}$ solution with and without the 
addition of $1 \mathrm{mM}$ 2-ABI are presented in Fig. 2. Two anodic peaks at $0.342 \mathrm{~V}$ and $0.503 \mathrm{~V}$ vs. SCE and one cathodic peak at $-0.460 \mathrm{~V} v s$. SCE were observed for copper immersed in $3 \mathrm{wt} \%$ $\mathrm{NaCl}$ solution.

The first anodic peak, $\mathrm{A}_{1}$, as designated in Fig. 2, indicates the formation of $\mathrm{CuCl}$ according to the electrochemical reaction shown in eqn (1).

$$
\mathrm{Cu}+\mathrm{Cl}^{-} \rightleftarrows \mathrm{CuCl}_{\mathrm{ads}}+\mathrm{e}^{-}
$$

The $\mathrm{CuCl}_{\mathrm{ads}}$ formed reacts further with the chloride ions present to form $\mathrm{CuCl}_{2}{ }^{-}$, according to the chemical reaction shown in eqn (2).

$$
\mathrm{CuCl}_{\mathrm{ads}}+\mathrm{Cl}^{-} \rightleftarrows \mathrm{CuCl}_{2}^{-}
$$

The second anodic peak $\mathrm{A}_{2}$, observed at more positive potentials, indicates the electrochemical formation of $\mathrm{Cu}^{2+}$ (eqn (3)).

$$
\mathrm{CuCl}_{2}^{-} \rightleftarrows \mathrm{Cu}^{2+}+2 \mathrm{Cl}^{-}+\mathrm{e}^{-}
$$

At more positive potentials than the $\mathrm{A}_{2}$ peak, a current plateau is observed, which represents the equilibrium between the dissolution of $\mathrm{CuCl}_{2}{ }^{-}$complex and the formation of a $\mathrm{CuCl}$ layer on the copper surface. ${ }^{17,30}$

When $1.000 \mathrm{~V} v s$. SCE was reached, the potential shifted to the cathodic direction. A small anodic reactivation peak, $\mathrm{A}_{\mathrm{r}}$, at $0.091 \mathrm{~V} v s$. SCE was observed. This peak can be formed either as a result of the oxidation of the patches of non-oxidized copper in the forward scan, or due to the formation of a poorly protective film in the forward scan, which enabled further oxidation even though the cathodic scan direction was applied. ${ }^{17}$ At even more negative potentials, it is possible that either cuprous chlorides or $\mathrm{Cu}^{2+}$ undergo reduction. The soluble $\mathrm{Cu}^{2+}$ species leave the electrode surface, while cuprous chlorides accumulate. ${ }^{42,43}$ Therefore, the only cathodic peak, $\mathrm{K}_{1}$, observed at $-0.460 \mathrm{~V} v s$. SCE, is related to the reduction of $\mathrm{CuCl}_{2}{ }^{-}$or $\mathrm{CuCl}^{17,30}$

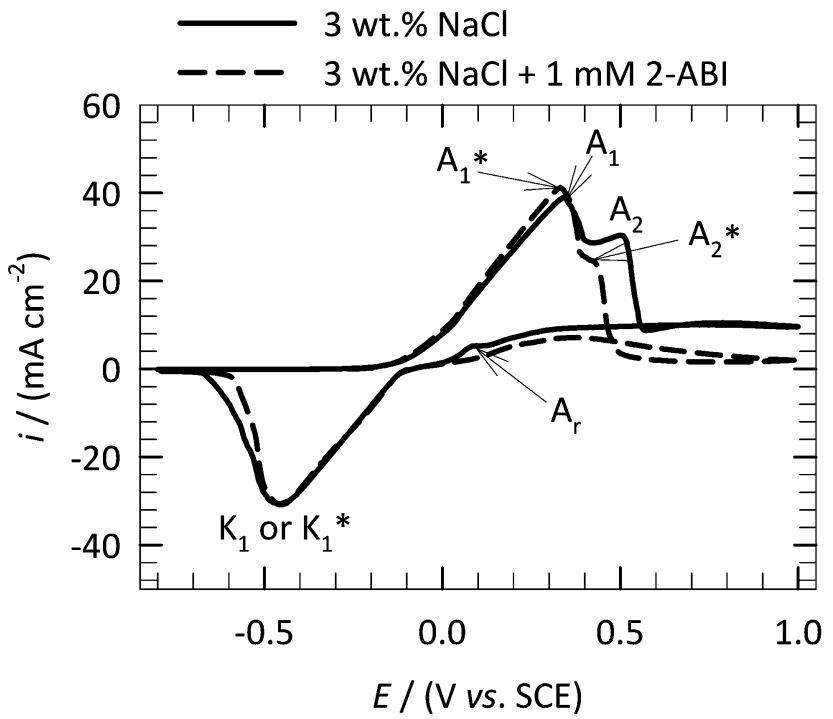

Fig. 2 CV curves for copper samples immersed in $3 \mathrm{wt} \% \mathrm{NaCl}$ solution at $25{ }^{\circ} \mathrm{C}$ with and without the addition of $1 \mathrm{mM}$ of $2-\mathrm{ABI}$ obtained with a $20 \mathrm{mV} \mathrm{s}^{-1}$ potential scan rate.
No significant change in the first current anodic peak, $\mathrm{A}_{1}$, was observed when $1 \mathrm{mM} 2$-ABI was added to the $3 \mathrm{wt} \% \mathrm{NaCl}$ solution. In fact, the first peak in the inhibited solution, denoted as $\mathrm{A}_{1}{ }^{*}$, was detected at $0.336 \mathrm{~V} v$ s. SCE. This indicates that the addition of 2-ABI does not inhibit the $\mathrm{Cu}(\mathrm{I})$ formation. As the potential increases towards more positive values, the second current anodic peak, $\mathrm{A}_{2}{ }^{*}$, in the inhibited solution is detected at $0.430 \mathrm{~V} v \mathrm{~s}$. SCE. The observed decrease in the $\mathrm{A}_{2}{ }^{*}$ peak (inhibited solution) compared to the $\mathrm{A}_{2}$ peak (non-inhibited solution), indicates that less $\mathrm{Cu}$ (II) is formed in the presence of 2-ABI. The current plateau in the inhibited solution is less intense, demonstrating that the corrosion of copper was inhibited by the formation of a 2-ABI surface layer on its surface (presumably a $\mathrm{Cu}(\mathrm{I}$ )-2-ABI complex was formed). Moreover, no reactivation peak was observed for the inhibited solution most likely due to full coverage of the surface, leaving no possibility of $\mathrm{Cu}$ oxidation.

One cathodic peak, $\mathrm{K}_{1}{ }^{*}$, was detected in the cathodic scan. The cathodic peak in the inhibited solution has the same intensity and peak potential position as the cathodic peak of the non-inhibited sample. However, a lower cathodic peak area (less electric charge passed) was observed, meaning that less $\mathrm{Cu}(\mathrm{I})$ was formed in the anodic scan, due to the inhibition process. This implies that the addition of 2-ABI does influence the formation of $\mathrm{Cu}(\mathrm{I})$.

\subsection{Chronopotentiometric measurements}

The $E v s$. $t$ measurements for the copper samples performed from the moment of immersion in $3 \mathrm{wt} \% \mathrm{NaCl}$ solution containing $1 \mathrm{mM}$ 2-ABI over $100 \mathrm{~h}$ of immersion are presented in Fig. 3. These measurements were performed in between the EIS measurements (at 1, 3, 5, 10, 30, 50, and $100 \mathrm{~h}$ of immersion), which is reflected in the discontinuous chronopotentiometric curve (indicated in Fig. 3). No significant change in the potential was observed after the EIS measurements.

A decrease in the potential was observed at the moment of copper immersion in the solution containing $2-\mathrm{ABI}$. The potential

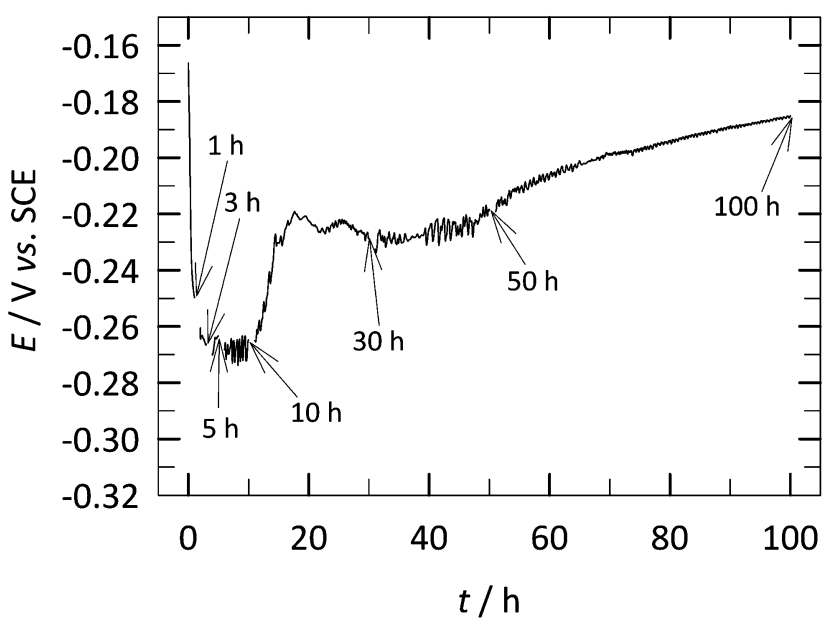

Fig. 3 Chronopotentiometric curve for the copper samples immersed in 3 wt\% $\mathrm{NaCl}$ solution at $25^{\circ} \mathrm{C}$ containing $1 \mathrm{mM} 2-\mathrm{ABI}$. The arrows show the times when the EIS measurements were performed (discontinuous curve). 
stabilized (no significant change was observed) between 1 and $10 \mathrm{~h}$ of immersion.

A significant increase in the potential was observed after $10 \mathrm{~h}$ of immersion. This potential increase was more pronounced between $10-30 \mathrm{~h}$ and after $50 \mathrm{~h}$ of immersion. After $100 \mathrm{~h}$ of immersion (before starting the PD measurement), a potential of $-0.185 \mathrm{~V} v$ s. SCE was measured. The addition of 2 -ABI to the $3 \mathrm{wt} \% \mathrm{NaCl}$ solution, after $100 \mathrm{~h}$ of immersion, caused a shift in the potential of the copper samples to more positive values. The potential of the copper samples immersed in non-inhibited $3 \mathrm{wt} \% \mathrm{NaCl}$ solution was previously reported to be $-0.263 \mathrm{~V} v s$. SCE. ${ }^{30}$ This potential shift is also an indication of the corrosion inhibition efficiency of this compound, which acts as an anodic-type inhibitor, making the whole system nobler.

\subsection{EIS measurements}

Fig. 4 shows the EIS spectra measured after 1 h, 3 h, 5 h, 10 h, $30 \mathrm{~h}, 50 \mathrm{~h}$ and $100 \mathrm{~h}$, at $25^{\circ} \mathrm{C}$, for copper samples immersed in $3 \mathrm{wt} \% \mathrm{NaCl}$ solution containing $1 \mathrm{mM} 2-\mathrm{ABI}$. The relatively long immersion time employed allows the achievement of a steadystate condition needed for the EIS spectra to be valid. ${ }^{44}$ EIS measurements for pure $\mathrm{Cu}$ immersed in non-inhibited $3 \mathrm{wt} \%$ $\mathrm{NaCl}$ solution were reported before. ${ }^{27}$

The EIS response of copper samples immersed in 2-ABI shows different behaviors in high (10-1000 kHz), middle (1-1000 Hz), and low (below $1 \mathrm{~Hz}$ ) frequency regions (Fig. 4). Typical resistor behavior is observed in the high frequency region when a horizontal amplitude is reached (Fig. 4b), while the phase angle approaches $0^{\circ}$ (Fig. 4c). The behavior in this case is attributed to an uncompensated resistance, $R_{\Omega}$, where the solution resistance has the largest contribution. In the middle region, a linear relationship between $|Z|$ and $f$ is observed ( $Z$ and $f$ are impedance and frequency, respectively). The slope of the response in this area is close to -1 (Fig. $4 \mathrm{~b}$ ) and the phase angle approaches $-90^{\circ}$ (Fig. 4c). These indicate typical capacitor behavior. In the low frequency region, no horizontal amplitude is observed, which would indicate the presence of diffusion and/or adsorption/desorption processes. ${ }^{14,27,28,30,44,45}$ Moreover, the low frequency region of the 2-ABI-inhibited samples after $100 \mathrm{~h}$ of immersion is shifted two orders of magnitude higher compared with the same region of the EIS spectra for copper in non-inhibited $3 \mathrm{wt} \% \mathrm{NaCl}$ solution reported previously. ${ }^{27}$ This is another indication of the corrosion inhibition efficiency of 2-ABI for copper in $3 \mathrm{wt} \% \mathrm{NaCl}$ solution. After $100 \mathrm{~h}$ of immersion, the low frequency region of the Bode plots (Fig. 4b) suggested similar resistive behaviour (similar $|Z|$ values) of 2-ABIinhibited samples compared with those inhibited by MePhI. ${ }^{30}$ Higher $|Z|$ values (a more resistive system) were observed for the same copper samples immersed in $3 \mathrm{wt} \% \mathrm{NaCl}$ solution containing $\mathrm{MBOH},{ }^{28} \mathrm{MBTH}^{29}$ and $\mathrm{MBIH} .{ }^{27}$

As described above, three relaxation processes were taken into consideration for the fitting procedure, including diffusion. No additional relaxation process was taken into consideration as it was not possible to separate it from the other processes. The EIS response of copper immersed in $3 \mathrm{wt} \% \mathrm{NaCl}$ solution containing $1 \mathrm{mM}$ 2-ABI was fitted using the nested equivalent electrical circuit (EEC) model $R_{\Omega}\left(Q_{1}\left(R_{1}\left(Q_{2}\left(R_{2}\left(Q_{3} R_{3}\right)\right)\right)\right)\right)$ shown in Fig. 5. The same EEC model (or $R_{\Omega}\left(Q_{1}\left(R_{1}\left(Q_{2}\left(R_{2} W\right)\right)\right)\right.$ ), where $W$ represents the element for the unrestricted diffusion) was used by Van Ingelgem et $a .^{45}$ to fit the EIS results for copper immersed in non-inhibited $0.4-0.6 \mathrm{M} \mathrm{NaCl}$ solutions. This EEC model is used to fit the response of an electrode coated with a porous layer. ${ }^{46-49}$ Similarly, three relaxation processes were considered for copper inhibited by $\mathrm{MBIH} .^{27}$ In contrast, four relaxation processes were taken into account in the case of $\mathrm{MBOH}-$ and MePhI-inhibited copper samples. ${ }^{28,30}$

The selected EEC model (Fig. 5) consists of three relaxation processes in series with the uncompensated resistance, $R_{\Omega}$. The solution resistance is the main contributor to the $R_{\Omega}$. The impedance of the constant phase element (CPE), described by $Q$ (the non-ideal capacitance), is given by eqn (4): ${ }^{50}$

$$
Z(\mathrm{CPE})=\left(Q(j \omega)^{n}\right)^{-1}
$$

The CPE describes an ideal capacitor for $n=1$, or the distribution of dielectric relaxation times in frequency space for $0.5<n<1$. The unrestricted diffusion is described for $n=0.5 .^{50}$

The first relaxation process, $R_{1} Q_{1}$, characterizes the surface layer, which consists of a combination of the $\mathrm{Cu}_{2} \mathrm{O}$ passive layer and the adsorption of 2-ABI on the surface of the copper samples. The second relaxation process, $R_{2} Q_{2}$, describes the charge transfer resistance, $R_{2}$, and the double-layer capacitance (described by $\left.Q_{2}\right)$. The diffusion of the ionic species $\left(\mathrm{Cu}^{2+}\right)$ from the metal surface to the bulk solution is described by the third relaxation process, $R_{3} Q_{3}$. A detailed explanation of why this is
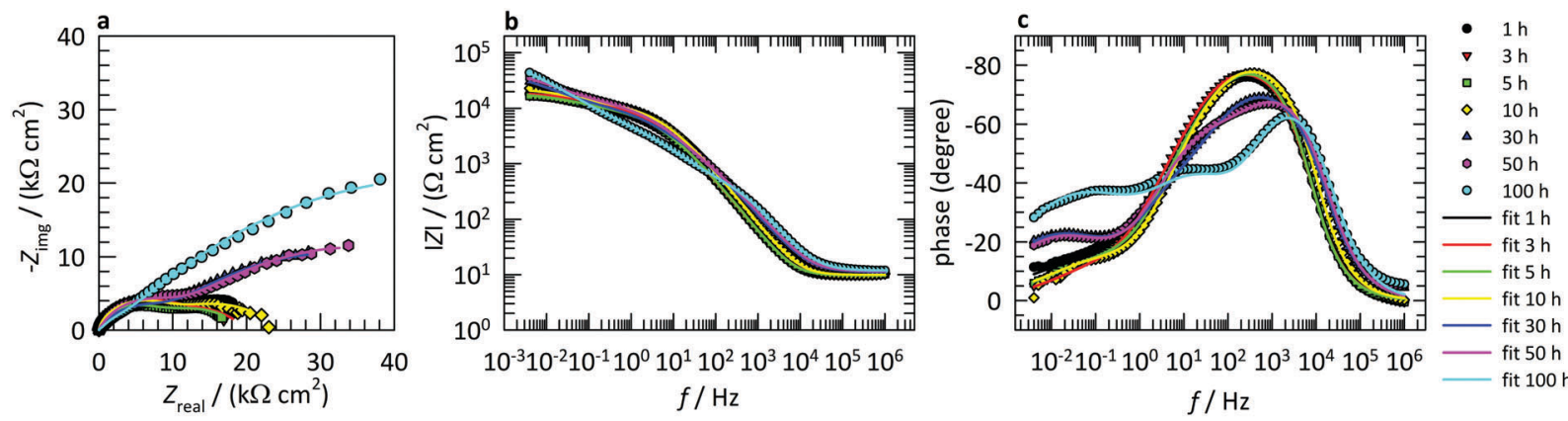

Fig. 4 The measured (dotted symbols) and fitted (solid line) EIS measurements for copper in 3 wt\% $\mathrm{NaCl}$ solution at $25^{\circ} \mathrm{C}$ containing $1 \mathrm{mM} 2$-ABI after $1,3,5,10,30,50$, and $100 \mathrm{~h}$ of immersion. The EIS response was fitted using the EEC model represented in Fig. 5. 


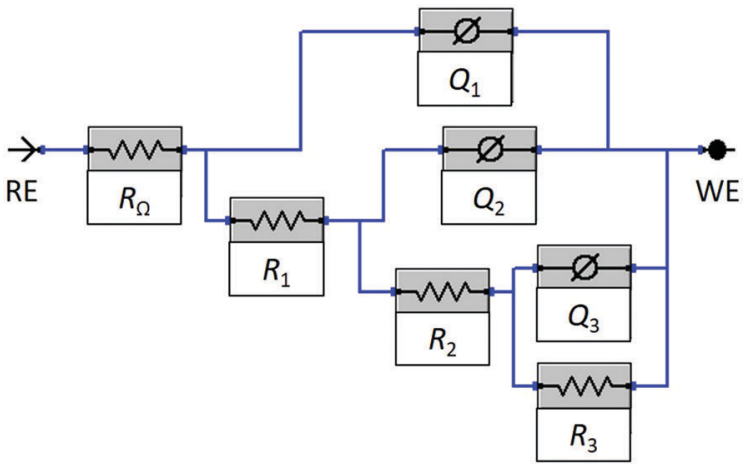

Fig. 5 The EEC model used to fit the EIS response.

described in such a manner is given below. The average values obtained by fitting the EIS response using the EEC model in Fig. 5 are presented in Table 1 . The capacitance $(C)$ values are calculated from the respective $Q$ values according to eqn (5):

$$
C_{x}=\left(R_{x} Q_{x}\right)^{1 / n_{x}} / R_{x}
$$

Fig. 6a presents the variation of the surface layer $\left(C_{1}\right)$ and double-layer capacitance $\left(C_{2}\right)$ with increasing immersion time from 1 to $100 \mathrm{~h}$. The calculation of $C_{3}$ was not relevant in this case since $Q_{3}$ describes unrestricted diffusion, as confirmed by the value of $n_{3}$ being close to 0.5 (Table 1 ). The higher the impedance of the diffusion process the slower the diffusion process occurs. ${ }^{27}$ Table 1 shows that the $Q_{3}$ value decreases with increasing the immersion time. This implies that the diffusion of the ionic species travelling through the surface layer is restricted due to the increase of the surface layer thickness with increasing immersion time (as can be seen below from the variation of the $C_{1}$ values with immersion time).

The thickness of the surface layer, $d$, is inversely proportional to the surface layer capacitance, $C_{1}$, as given in eqn (6):

$$
d=\frac{\left(\varepsilon_{0} \varepsilon A\right)}{C_{1}}
$$

where $\varepsilon_{0}$ is the permittivity of a vacuum $\left(8.85 \times 10^{-14} \mathrm{~F} \mathrm{~cm}^{-1}\right)$, $\varepsilon$ is the dielectric constant, and $A$ is the geometric area of the electrode $\left(1 \mathrm{~cm}^{2}\right)$.

The $C_{1}$ values calculated according to eqn (5) decrease with increasing immersion time (Fig. 6a), which implies an increase of the surface layer thickness. This increase is connected to the
$\mathrm{Cu}_{2} \mathrm{O}$ passive layer and the adsorption of the 2-ABI on the copper surface.

The double-layer capacitance is connected to the active part of the surface area. The higher this capacitance, the smaller the surface covered by the corrosion inhibitor or oxide. ${ }^{51}$ The $C_{2}$ values decrease up to $10 \mathrm{~h}$ of immersion, due to the adsorption of 2-ABI, which covers the active parts on the copper surface. Then, the double-layer capacitance increased between 10 and $30 \mathrm{~h}$ of immersion and decreased again between 30 and $50 \mathrm{~h}$ of immersion. An increase in $C_{2}$ was observed after $50 \mathrm{~h}$ of immersion. This behaviour is most likely connected with the competitive process of corrosion, which opens the active surface area, the formation of copper oxides, and the adsorption of the corrosion inhibitor, which covers the active surface area with increasing immersion time.

The resistance of the copper samples to general corrosion can be evaluated from the polarization resistance, $R_{\mathrm{p}}$. The higher the $R_{\mathrm{p}}$, the more resistant the metal. Fig. $6 \mathrm{~b}$ presents the variation of $R_{\mathrm{p}}\left(R_{\mathrm{p}}=R_{1}+R_{2}+R_{3}\right)$ with immersion time. No significant change in the $R_{\mathrm{p}}$ was observed for up to $5 \mathrm{~h}$ of immersion, and after that the polarization resistance increased with immersion time, showing the improved corrosion resistance of such a system with increasing immersion time and proving the corrosion inhibition ability of 2-ABI.

\subsection{PD curve measurements}

The potentiodynamic curves for the copper samples after $100 \mathrm{~h}$ of immersion in $3 \mathrm{wt} \% \mathrm{NaCl}$ solution at $25{ }^{\circ} \mathrm{C}$ containing $1 \mathrm{mM}$ 2-ABI are presented in Fig. 7. The PD curve of the non-inhibited copper samples immersed in $3 \mathrm{wt} \% \mathrm{NaCl}$ solution, presented previously, ${ }^{14}$ is given for comparison. In order to avoid the effects of capacitance and to ensure that the current/voltage relationship only reflects the interfacial corrosion process at every potential of the polarization scan, a scan rate of $0.1 \mathrm{mV} \mathrm{s}^{-1}$ was employed. ${ }^{44,52}$

In the studied solutions, hydrogen ions and dissolved oxygen are the only species that can be reduced in solution. The PD curve measurements were started at high potential values $\left(-0.250 \mathrm{~V}\right.$ vs. $\left.E_{\mathrm{oc}}\right)$, at which the cathodic potentiodynamic behaviour of copper is determined by hydrogen evolution. ${ }^{45}$ The mass-transport-controlled reduction of dissolved oxygen characterizes the potentiodynamic behaviour for potential values closer to $E_{\text {corr }}$ Bacarella et al. ${ }^{53}$ suggested that at more positive potentials than $E_{\text {corr }}$, anodic electrodissolution of copper from

Table 1 Fitted EIS parameters for copper samples immersed for $1,3,5,10,30,50$, and $100 \mathrm{~h}$, in $3 \mathrm{wt} \% \mathrm{NaCl}$ solution containing $1 \mathrm{mM} 2-\mathrm{ABI}$ at $25^{\circ} \mathrm{C}$,

\begin{tabular}{|c|c|c|c|c|c|c|c|c|c|c|c|}
\hline Immersion time [h] & $\chi^{2}$ & $R_{\Omega}$ & $n_{1}$ & $R_{1}$ & $Q_{1}$ & $n_{2}$ & $R_{2}$ & $Q_{2}$ & $n_{3}$ & $R_{3}$ & $Q_{3}$ \\
\hline 1 & 0.25 & 9.6 & 0.90 & 4.48 & 5.97 & 0.67 & 8.07 & 37.92 & 0.51 & 12.56 & 346.30 \\
\hline 3 & 0.20 & 9.7 & 0.91 & 4.34 & 5.78 & 0.65 & 7.61 & 23.30 & 0.54 & 7.92 & 256.80 \\
\hline 5 & 0.20 & 9.7 & 0.92 & 3.27 & 5.22 & 0.66 & 5.83 & 20.23 & 0.51 & 10.48 & 218.30 \\
\hline 10 & 0.24 & 9.9 & 0.92 & 4.53 & 3.77 & 0.66 & 6.19 & 15.54 & 0.51 & 13.50 & 172.30 \\
\hline 30 & 0.55 & 11.1 & 0.84 & 2.96 & 5.56 & 0.64 & 7.58 & 22.21 & 0.53 & 44.38 & 194.50 \\
\hline 50 & 0.60 & 11.5 & 0.86 & 1.10 & 4.01 & 0.64 & 10.70 & 11.48 & 0.53 & 48.53 & 169.10 \\
\hline 100 & 0.93 & 11.8 & 0.86 & 0.53 & 3.08 & 0.65 & 5.19 & 34.67 & 0.53 & 86.94 & 102.30 \\
\hline
\end{tabular}
obtained using the $R_{\Omega}\left(Q_{1}\left(R_{1}\left(Q_{2}\left(R_{2}\left(Q_{3} R_{3}\right)\right)\right)\right)\right.$ EEC model represented in Fig. 5. Units: $\chi^{2}\left[\times 10^{-3}\right], R_{\Omega}\left[\Omega \mathrm{cm}^{2}\right], R_{1}, R_{2}$ and $R_{3}\left[\mathrm{k} \Omega \mathrm{cm}^{2}\right]$, and $Q\left[\mu S \mathrm{~cm}{ }^{-2} \mathrm{~s}^{n}\right]$ 

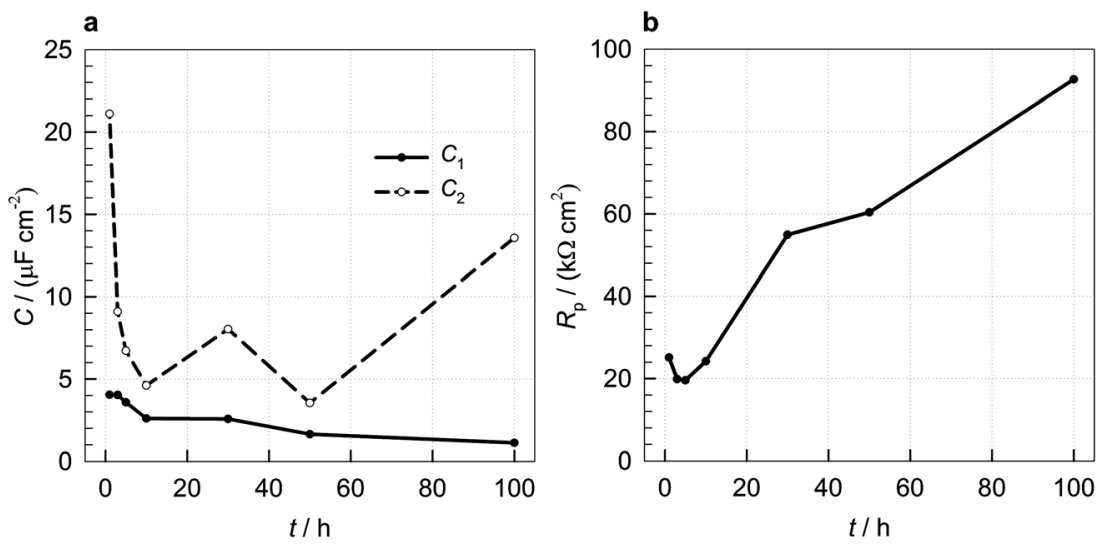

Fig. 6 Variation of (a) capacitance $(C)$ and (b) $R_{\mathrm{p}}$ values with increasing immersion time for copper samples immersed in 3 wt\% $\mathrm{NaCl}$ solution at $25{ }^{\circ} \mathrm{C}$ containing $1 \mathrm{mM}$ 2-ABI

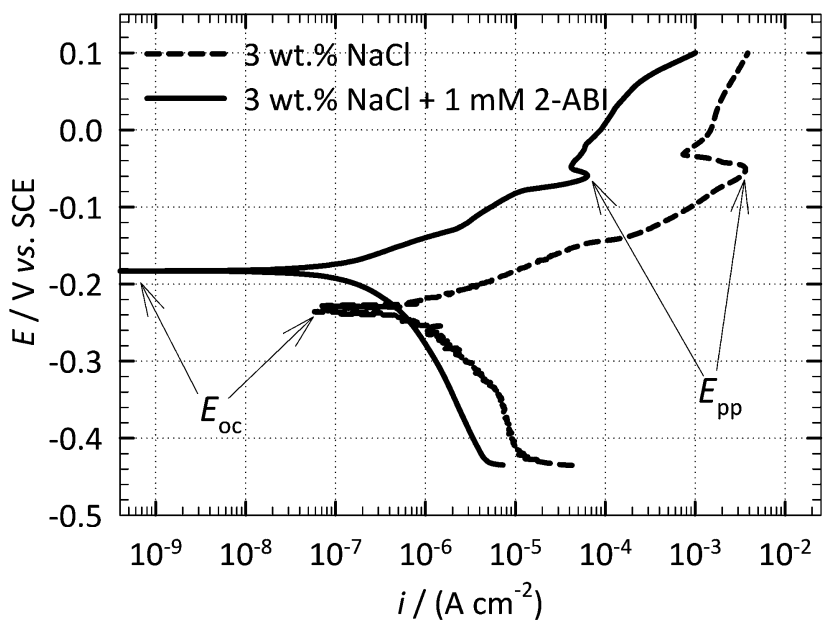

Fig. 7 PD curve measurements for copper samples after $100 \mathrm{~h}$ of immersion in 3 wt\% $\mathrm{NaCl}$ solution at $25{ }^{\circ} \mathrm{C}$ containing $1 \mathrm{mM} 2-\mathrm{ABI}$ compared with the non-inhibited samples. ${ }^{14}$

$\mathrm{Cu}$ to $\mathrm{Cu}(\mathrm{I})$ occurs and $\mathrm{CuCl}$ is formed according to eqn (1). Soluble $\mathrm{CuCl}_{2}{ }^{-}$is then formed when $\mathrm{CuCl}$ reacts with $\mathrm{Cl}^{-}$ according to eqn (2). The formed $\mathrm{CuCl}_{2}{ }^{-}$diffuses from the outer Helmholtz plane into the bulk solution. ${ }^{53,54}$ A linear relationship between the potential and $\log i$ is observed in the active part of the curve. The linearity is interrupted when the primary passivation potential, $E_{\mathrm{pp}}$, is reached. At this potential, $\mathrm{CuCl}$ starts to predominate as the $\mathrm{CuCl}_{2}^{-}$activity exceeds its solubility. The $E_{\mathrm{pp}}$ in the case of non-inhibited copper samples in $3 \mathrm{wt} \%$ $\mathrm{NaCl}$ was reported to be $-0.035 \mathrm{~V}$ vs. $\mathrm{SCE},{ }^{14}$ while for the 2-ABI-inhibited sample this potential was shifted to more negative values $\left(E_{\mathrm{pp}}=-0.059 \mathrm{~V}\right.$ vs. SCE).

The $E_{\mathrm{oc}}$ of the copper samples was shifted to more positive potentials when $1 \mathrm{mM}$ 2-ABI was added into the $3 \mathrm{wt} \% \mathrm{NaCl}$ solution (Fig. 7), confirming the chronopotentiometric measurements explained above. A decrease in both anodic and cathodic current densities was observed for the 2-ABI-inhibited sample compared with the non-inhibited sample. However, the decrease was more pronounced in the anodic part of the PD curve.
In addition, the $E_{\text {corr }}$ of the samples inhibited with 2-ABI shifted to the anodic direction, while the corrosion current density $\left(i_{\text {corr }}\right)$ was reduced by about one order of magnitude compared with the noninhibited sample. In conclusion, 2-ABI acted as a mixed-type inhibitor, with a more pronounced action on the anodic corrosion reaction. The same mixed-type inhibition behavior was also reported previously for $\mathrm{MBIH},{ }^{27} \mathrm{MBOH},{ }^{28} \mathrm{MBTH},{ }^{29}$ and $\mathrm{BTAH},{ }^{14}$ while BTAOH acted as a weak mixed-type inhibitor. ${ }^{14}$

\subsection{Surface characterization}

In order to be able to make a comparison with the results obtained by the electrochemical measurements, the same sample preparation and treatment procedure was used for the surface analysis. Both contact angle and ATR-FTIR measurements were performed after $1 \mathrm{~h}$ of immersion. This immersion time allows an analysis of the first few inhibitor layers that were adsorbed on the copper surface. Crystallites of the corrosion inhibitor will form on the surface of the samples for longer immersion times. These crystallites usually have no influence on the corrosion inhibition action of the adsorbed compound. ${ }^{55}$

A significantly higher immersion time, 31 days, was chosen for the topography and morphology measurements of the samples immersed in $3 \mathrm{wt} \% \mathrm{NaCl}$ solution with and without the addition of 2-ABI in order to induce the corrosion action of the medium used.

3.6.1 ATR-FTIR measurements. The ATR-FTIR spectra of the ground copper samples immersed for $1 \mathrm{~h}$ in $3 \mathrm{wt} \% \mathrm{NaCl}$ solution, with and without the addition of $1 \mathrm{mM} 2-\mathrm{ABI}$ are presented in Fig. 8. No characteristic adsorption bands suggesting organic species adsorption were observed for the noninhibited copper sample. Several peaks were identified for the inhibited sample. The presence of the amine group was confirmed by the $-\mathrm{NH}_{2}$ symmetric stretching $\left(3375 \mathrm{~cm}^{-1}\right)$ and the $-\mathrm{NH}_{2}$ asymmetric stretching $\left(3470 \mathrm{~cm}^{-1}\right)$ peaks, in addition to the $-\mathrm{NH}_{2}$ scissoring (1610 and $1586 \mathrm{~cm}^{-1}$ ) and the $-\mathrm{NH}_{2}$ wagging $\left(744 \mathrm{~cm}^{-1}\right)$ modes. $^{56-58}$ The two expressed peaks at 1500 and $1460 \mathrm{~cm}^{-1}$ are attributed to the aromatic $\mathrm{C}-\mathrm{C}$ stretching. ${ }^{59}$ The $\mathrm{C}-\mathrm{N}$ bond vibration is represented by an expressed peak at $1284 \mathrm{~cm}^{-1} \cdot{ }^{56}$ This peak could alternatively 


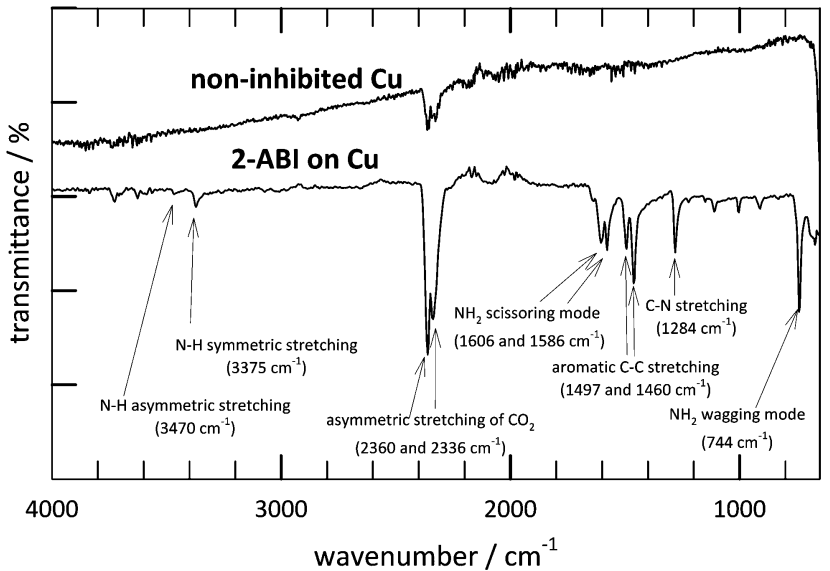

Fig. 8 ATR-FTIR spectra of the ground copper sample immersed for $1 \mathrm{~h}$ in 3 wt $\% \mathrm{NaCl}$ solution at $25^{\circ} \mathrm{C}$ with and without the addition of $1 \mathrm{mM} 2-\mathrm{ABI}$.

be attributed to $\mathrm{C}=\mathrm{N}$ stretching in the imidazole ring. ${ }^{60}$ Sudha et al. ${ }^{57}$ attributed the peak at $907 \mathrm{~cm}^{-1}$ to the $\mathrm{C}-\mathrm{C}-\mathrm{C}$ in-plane bending modes of 2-ABI.

Finally, for both the inhibited and non-inhibited samples two peaks at 2360 and $2336 \mathrm{~cm}^{-1}$ were observed, which can be attributed to the asymmetric stretching of $\mathrm{CO}_{2} \cdot{ }^{61}$ The absence of a broad band between 2600 and $3400 \mathrm{~cm}^{-1}$ related to $\mathrm{O}-\mathrm{H}$ stretching is an indication that no significant amount of water molecules remained on the surface after the drying procedure. ${ }^{26}$

3.6.2 Contact angle measurements. The average contact angles of the copper samples immersed in $3 \mathrm{wt} \% \mathrm{NaCl}$ at $25{ }^{\circ} \mathrm{C}$ with and without the addition of $1 \mathrm{mM}$ 2-ABI (three samples for each, measured in three different spots), as well as the drop shapes on the surface are presented in Table 2. In addition, a $95 \%$ confidence interval, calculated as $\pm t s \sqrt{ } N$, ( $t$-Student's distribution, $s$-standard deviation, $N$-number of measurements) ${ }^{41}$ is also given.

As reported previously, ${ }^{30}$ the contact angle of the copper samples immersed in non-inhibited $3 \mathrm{wt} \% \mathrm{NaCl}$ solution was found to be $43.0^{\circ} \pm 4.4^{\circ}$. The hydrophilic nature of the copper samples was significantly reduced by the adsorption of 2-ABI on their surface. In fact, the contact angle of the copper samples immersed in $3 \mathrm{wt} \% \mathrm{NaCl}$ solution containing $1 \mathrm{mM}$ 2-ABI was found to be $84.8^{\circ} \pm 2.6^{\circ}$. The adsorption of 2-ABI resulted in a more hydrophobic copper sample compared with the adsorption of MePhI reported previously (a contact angle of $\left.68.7^{\circ} \pm 2.9^{\circ}\right) .^{30}$

3.6.3 Topography and morphology analysis. The topography of the copper samples immersed for 31 days in $3 \mathrm{wt} \% \mathrm{NaCl}$ solution with and without the addition of $1 \mathrm{mM} 2$-ABI was obtained by 3D-profilometry. The mean surface roughness, $S_{\mathrm{a}}$, is calculated according to eqn (7). ${ }^{62} L_{x}, L_{y}$, and $z(x, y)$ are, respectively, the acquisition lengths of the surface in the $x$ and $y$ directions and the height. The corrosion susceptibility of the metal increases with increasing $S_{\text {a }}$ value. ${ }^{62}$

$$
S_{\mathrm{a}}=\frac{1}{L_{x}} \frac{1}{L_{y}} \int_{0}^{L_{x}} \int_{0}^{L_{y}}|z(x, y)| \mathrm{d} x \mathrm{~d} y
$$

The calculated $S_{\mathrm{a}}$ value for the sample immersed for 31 days in non-inhibited $3 \mathrm{wt} \% \mathrm{NaCl}$ solution is $0.855 \mu \mathrm{m}$ and $0.139 \mu \mathrm{m}$ for the sample immersed in $3 \mathrm{wt} \% \mathrm{NaCl}$ solution containing $1 \mathrm{mM}$ 2-ABI. The adsorption of 2-ABI on the copper sample significantly reduced the copper surface roughness, proving its high corrosion inhibition ability. The representative 3Dprofiles for both inhibited and non-inhibited samples are given in Fig. 9.

The surface morphology of the copper samples after 31 days of immersion in $3 \mathrm{wt} \% \mathrm{NaCl}$ solution with and without addition of $1 \mathrm{mM}$ 2-ABI is presented in Fig. 10. As seen in Fig. 10a-c, general corrosion is the main corrosion type for the noninhibited copper samples and the corrosion products remain on the surface even after rinsing with ultrapure water. A more significantly corroded surface for the non-inhibited samples (Fig. 10a-c) compared with the less rough surface for the 2-ABIinhibited samples (Fig. 10d-f) was observed. Therefore, FE-SEM analyses are in accordance with the 3D-profilometry measurements (Fig. 9), confirming once more the corrosion inhibition effectiveness of 2-ABI.

Table 2 The average contact angles and the respective confidence intervals for copper samples immersed for $1 \mathrm{~h}$ in 3 wt $\% \mathrm{NaCl}$ solution at $25{ }^{\circ} \mathrm{C}$ with and without the addition of $1 \mathrm{mM} 2-\mathrm{ABI}$

Sample description
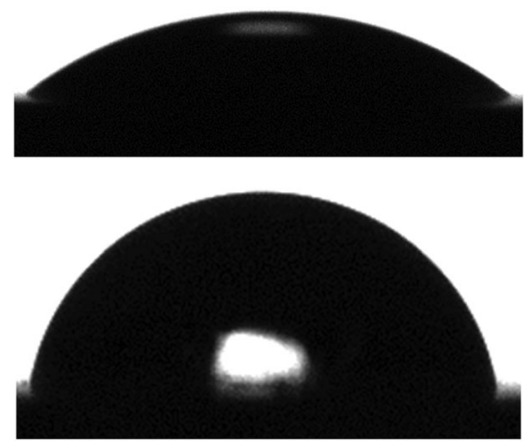

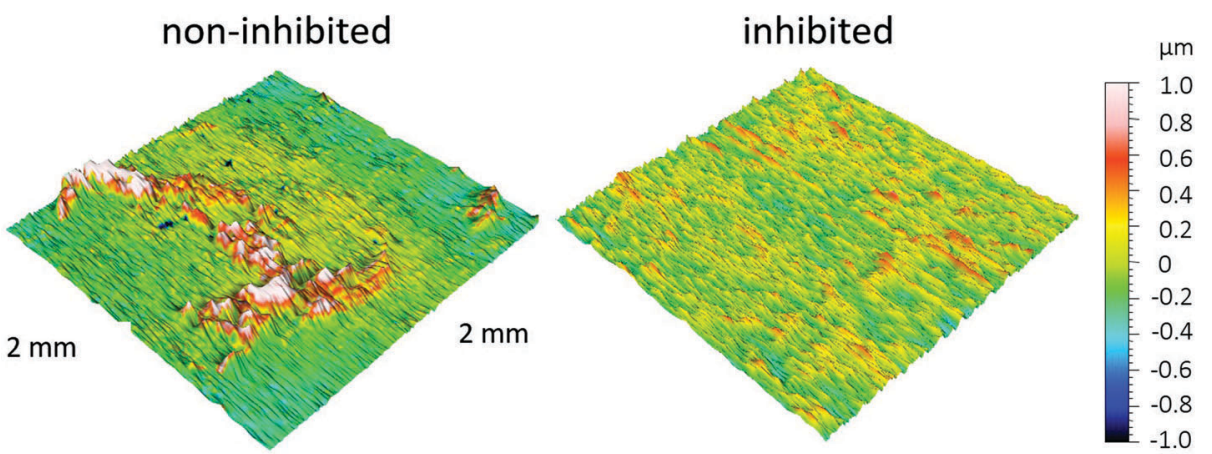

Fig. $93 \mathrm{D}$ profiles of the ground copper samples after immersion for 31 days in $3 \mathrm{wt} \% \mathrm{NaCl}$ solution, with and without the addition of $1 \mathrm{mM} 2$-ABI.

3 wt.\% NaCl
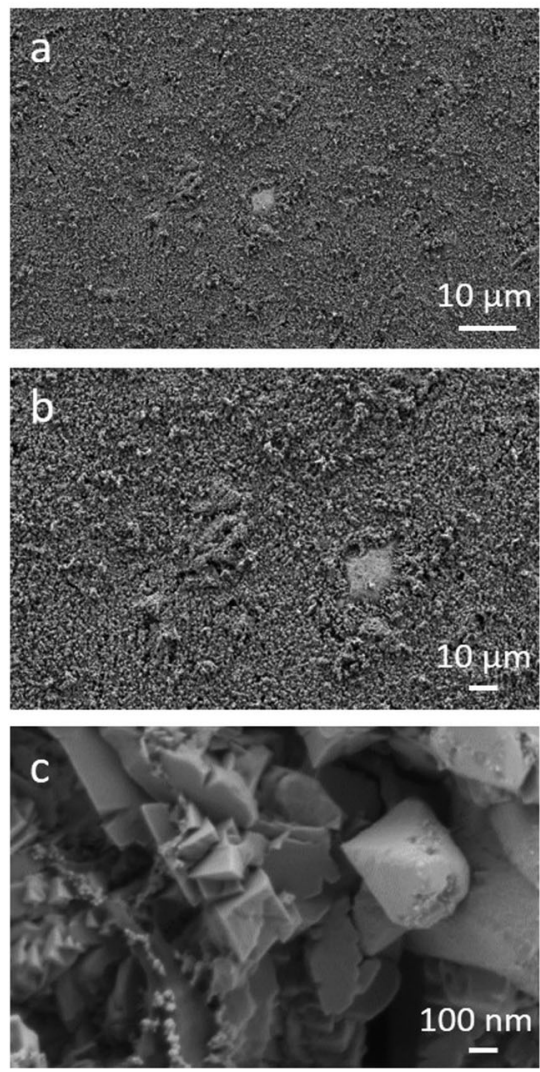

3 wt. $\% \mathrm{NaCl}+1 \mathrm{mM} 2-\mathrm{ABI}$
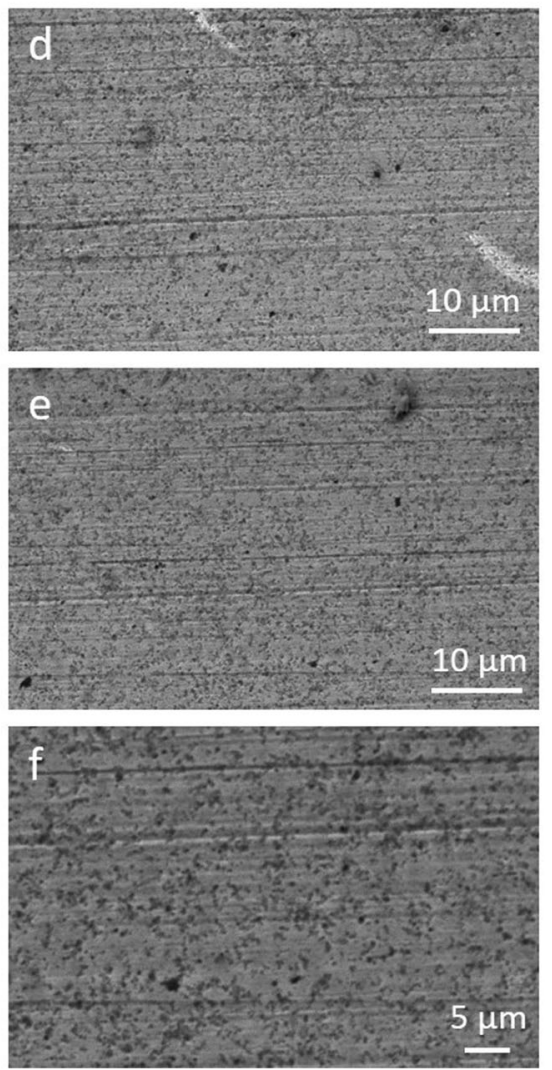

Fig. 10 FE-SEM micrographs of copper samples immersed for 31 days in $3 \mathrm{wt} \% \mathrm{NaCl}$ solution without (a-c) and with (d-f) addition of 1 mM 2-ABI.

\section{Conclusions}

The influence of 2-ABI as a corrosion inhibitor for copper in $3 \mathrm{wt} \% \mathrm{NaCl}$ solution at $25{ }^{\circ} \mathrm{C}$ was investigated by employing electrochemical and surface analytical techniques. Short-time immersion CV measurements showed that the addition of 2-ABI does not inhibit the oxidation of $\mathrm{Cu}$ to $\mathrm{Cu}(\mathrm{I})$, but inhibits the oxidation of $\mathrm{Cu}(\mathrm{I})$ to $\mathrm{Cu}(\mathrm{II})$. 2-ABI acted as a mixed-type inhibitor, with a predominant action on the anodic corrosion reaction. The corrosion of copper in $3 \mathrm{wt} \% \mathrm{NaCl}$ solution in the presence of $1 \mathrm{mM}$ 2-ABI was found to be under mixed control, following both kinetic- and diffusion-controlled processes. The corrosion resistance of the copper samples in 2-ABI-inhibited solution increased with immersion time. 2-ABI was absorbed on the copper surface, as confirmed by ATR-FTIR. The surface roughness of the samples decreased, resulting in a more hydrophobic surface.

\section{Acknowledgements}

The authors would like to acknowledge the financial support for this project received from the Slovenian Research Agency (grant numbers: BI-HR/16-17-046 and P2-0032). 


\section{References}

1 C. A. C. Sequeira, in Uhlig's corrosion handbook, ed. R. Winston Revie, John Wiley \& Sons Inc., New York, 3rd edn, 2011, pp. 757-786.

2 A. Cohen, in ASM Handbook, ed. S. D. Cramer and J. B. S. Covino, ASM International, vol. 13B, 2005, Corrosion Materials.

3 R. W. Revie and H. H. Uhlig, Corrosion and corrosion control: an introduction to corrosion science and engineering, John Wiley \& Sons, Inc., Hoboken, New Yersey, 4th edn, 2008.

4 M. Finšgar and I. Milošev, Corros. Sci., 2010, 52, 2737-2749.

5 A. I. Muñoz, J. G. Antón, J. L. Guiñón and V. P. Herranz, Electrochim. Acta, 2004, 50, 957-966.

6 A. L. K. Tan and A. M. Soutar, Thin Solid Films, 2008, 516, 5706-5709.

7 C. Liang, P. Wang, B. Wu and N. Huang, J. Solid State Electrochem., 2010, 14, 1391-1399.

8 M. M. Antonijević and M. B. Petrović, Int. J. Electrochem. Sci., 2008, 3, 1-28.

9 M. Mihit, K. Laarej, H. Abou El Makarim, L. Bazzi, R. Salghi and B. Hammouti, Arabian J. Chem., 2010, 3, 55-60.

10 R. Subramanian and V. Lakshminarayanan, Corros. Sci., 2002, 44, 535-554.

11 A. Lalitha, S. Ramesh and S. Rajeswari, Electrochim. Acta, 2005, 51, 47-55.

12 H. Bi, G. T. Burstein, B. B. Rodriguez and G. Kawaley, Corros. Sci., 2016, 102, 510-516.

13 M. Finšgar, Corros. Sci., 2013, 77, 350-359.

14 M. Finšgar, A. Lesar, A. Kokalj and I. Milošev, Electrochim. Acta, 2008, 53, 8287-8297.

15 P. F. Khan, V. Shanthi, R. K. Babu, S. Muralidharan and R. C. Barik, J. Environ. Chem. Eng., 2015, 3, 10-19.

16 T. Kosec, D. K. Merl and I. Milošev, Corros. Sci., 2008, 50, 1987-1997.

17 M. Finšgar, I. Milošev and B. Pihlar, Acta Chim. Slov., 2007, 54, 591-597.

18 J. J. Santana, M. Pähler, W. Schuhmann and R. M. Souto, ChemPlusChem, 2012, 77, 707-712.

19 M. M. Antonijević, S. M. Milić and M. B. Petrović, Corros. Sci., 2009, 51, 1228-1237.

20 A. M. Abdullah, F. M. Al-Kharafi and B. G. Ateya, Scr. Mater., 2006, 54, 1673-1677.

21 L. Tommesani, G. Brunoro, A. Frignani, C. Monticelli and M. Dal Colle, Corros. Sci., 1997, 39, 1221-1237.

22 A. Frignani, L. Tommesani, G. Brunoro, C. Monticelli and M. Fogagnolo, Corros. Sci., 1999, 41, 1205-1215.

23 N. Kovačević, I. Milošev and A. Kokalj, Corros. Sci., 2015, 98, 457-470.

24 H. Otmacic Curkovic, E. Stupnisek-Lisac and H. Takenouti, Corros. Sci., 2010, 52, 398-405.

25 H. Otmačić and E. Stupnišek-Lisac, Electrochim. Acta, 2003, 48, 985-991.

26 M. Finšgar, Corros. Sci., 2013, 72, 90-98.

27 M. Finšgar, Corros. Sci., 2013, 72, 82-89.

28 M. Finšgar and D. Kek Merl, Corros. Sci., 2014, 80, 82-95.
29 M. Finšgar and D. Kek Merl, Corros. Sci., 2014, 83, 164-175. 30 M. Finsgar, Int. J. Electrochem. Sci., 2016, 11, 6775-6790.

31 S. K. Bag, S. B. Chakraborty, A. Roy and S. R. Chaudhuri, Br. Corros. J., 1996, 31, 207-212.

32 S. K. Bag, S. B. Chakraborty and S. R. Chaudhuri, J. Indian Chem. Soc., 1993, 70, 24-30.

33 W. Zhang, R. Ma, S. Li, Y. Liu and L. Niu, Chem. Res. Chin. Univ., 2016, 32, 827-837.

34 M. M. Kabanda, L. C. Murulana, M. Ozcan, F. Karadag, I. Dehri, I. B. Obot and E. E. Ebenso, Int. J. Electrochem. Sci., 2012, 7, 5035-5056.

35 A. Ghanbari, M. M. Attar and M. Mahdavian, Mater. Chem. Phys., 2010, 124, 1205-1209.

36 A. K. Popova, M. S. Machkova, A. G. Djambova, A. Zwetanova and S. N. Raicheva, Bulg. Chem. Commun., 2008, 40, 300-305.

37 G. Gece and S. Bilgic, Corros. Sci., 2009, 51, 1876-1878.

38 M. Şahin, S. Bilgiç and H. Yılmaz, Appl. Surf. Sci., 2002, 195, 1-7.

39 M. Finšgar, B. Petovar, K. Xhanari and U. Maver, Corros. Sci., 2016, 111, 370-381.

40 M. Finšgar and J. Jackson, Corros. Sci., 2014, 86, 17-41.

41 D. L. Massart, B. G. M. Vandeginste, L. M. C. Buydens, S. D. Jong, P. J. Lewi and J. Smeyers-Verbeke, Handbook of Chemometrics and Qualimetrics: Part A, Elsevier, Amsterdam, 1997.

42 H. P. Lee and K. Nobe, J. Electrochem. Soc., 1986, 133, 2035-2043.

43 H. Otmačić, J. Telegdi, K. Papp and E. Stupnišek-Lisac, J. Appl. Electrochem., 2004, 34, 545-550.

44 D. C. Silverman, in Uhlig Corrosion Handbook, ed. R. W. Revie, John Wiley and Sons, New York, 2000, pp. 1179-1225.

45 Y. Van Ingelgem, E. Tourwé, J. Vereecken and A. Hubin, Electrochim. Acta, 2008, 53, 7523-7530.

46 K. Rahmouni, M. Keddam, A. Srhiri and H. Takenouti, Corros. Sci., 2005, 47, 3249-3266.

47 M. E. Orazem and B. Tribollet, Electrochemical Impedance Spectroscopy, John Wiley \& Sons Inc., Hoboken, New Jersey, 2008.

48 E. M. Sherif and S.-M. Park, J. Electrochem. Soc., 2005, 152, B428-B433.

49 B. Trachli, M. Keddam, H. Takenouti and A. Srhiri, Corros. Sci., 2002, 44, 997-1008.

50 I. D. Raistrick, D. R. Franceschetti and J. R. Macdonald, Impedance spectroscopy theory, experiment and application, John Wiley \& Sons Inc., Hoboken, New Jersey, 2nd edn, 2005.

51 D. Kek Merl, P. Panjan and J. Kovač, Corros. Sci., 2013, 69, 359-368.

52 F. Mansfeld and M. Kendig, Corrosion, 1981, 37, 545-546.

53 A. L. Bacarella and J. C. Griess, Journal of Electrochemistry Society, 1973, 120, 459-465.

54 D. Tromans and R. H. Sun, Journal of Electrochemistry Society, 1991, 138, 3235-3244.

55 M. Finsgar, Anal. Methods, 2015, 7, 6496-6503. 
56 E. Pretsch, P. Bühlmann and M. Badertscher, Structure determination of organic compounds, Springer-Verlag, Berlin, Heidelberg, 2009.

57 S. Sudha, M. Karabacak, M. Kurt, M. Cinar and N. Sundaraganesan, Spectrochim. Acta, Part A, 2011, 84, 184-195.

58 G. Socrates, Infrared and Raman characteristic group frequencies: tables and charts, John Wiley \& Sons, Chichester, 2004.
59 G. Varsányi and L. Láng, Assignments of vibrational spectra of seven hundred benzene derivatives, Wiley, New York, 1974.

60 M. Silverstein, G. C. Basseler and C. Morill, Spectrometric identification of organic compounds, Wiley, New York, 1981.

61 P. A. Gerakines, W. A. Schutte, J. M. Greenberg and E. F. van Dishoeck, Astron. Astrophys., 1994, 296, 810-826.

62 M. Finšgar, Corros. Sci., 2013, 72, 82-89. 